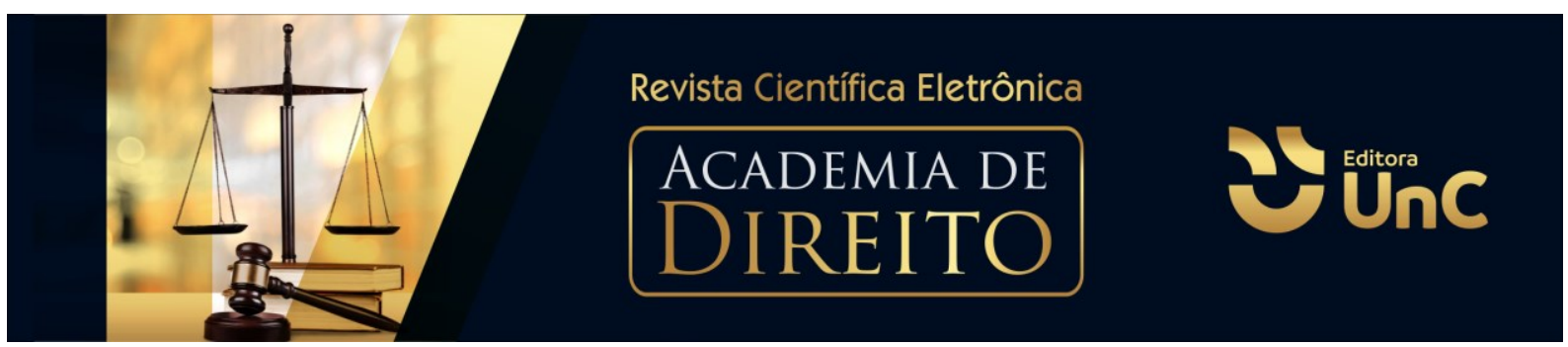

\title{
CAMINHOS PARA MUDANÇA PARADIGMÁTICA COM RELAÇÃO AO DIREITO ANIMAL E COMBATE AOS MAUS-TRATOS
}

\section{PATHWAYS TO PARADIGMATIC CHANGE IN RELATION TO ANIMAL LAW AND FIGHT AGAINST MISTREATMENT}

Gabriela Silva Schlichting Batista ${ }^{1}$

Alan Pinheiro de Paula ${ }^{2}$

\begin{abstract}
RESUMO
A pesquisa aborda a questão do Direito Animal com foco no desenvolvimento das medidas de proteção contra abusos e maus-tratos. O tema tem evocado debates em todo o mundo, e vem conquistando maior visibilidade, atenção e interesse com a repercussão das denúncias de práticas de abusos e maus-tratos. Seguindo a metodologia de pesquisa bibliográfica, aborda-se a questão em três aspectos: primeiramente, uma apresentação a nível histórico e teórico, onde é enfatizada a predominância da concepção antropocêntrica e as críticas hodiernas que a ela se destinam. Observa-se que a noção de "senciência" tem sido o pivô para uma alteração do paradigma que concerne à causa animal. Em seguida, passa-se a considerar as leis de proteção em vigor no Brasil, bem como as justificativas para a última proposta de alteração, do final de 2019 , e o registro das anteriores. Por fim, levanta-se as seguintes perguntas: as penalidades impostas por maus tratos no âmbito nacional seriam adequadas e suficientes? Comparativamente, com relação à legislação de outros países, em que pé se encontra o aparato jurídico específico? Conclui-se afirmando que, ainda que o acirramento das medidas punitivas desempenhem papel especial na resolução dos casos de abuso, uma modificação significativa só se dará através da atualização do aspecto técnico-jurídico numa consonância com o eixo ético-filosófico.
\end{abstract}

Palavras-Chave: Direito Animal. Maus-tratos. Legislação.

\footnotetext{
${ }^{1}$ Graduanda em Direito, Universidade do Contestado, Campus Mafra. Santa Catarina. Brasil. E-mail: gabischlichting17@gmail.com

${ }^{2}$ Mestre em Ciência Jurídica pela Universidade do Vale do Itajaí (UNIVALI). Especialista em Gestão de Segurança Pública pela Universidade do Sul de Santa Catarina (UNISUL). Especialista em Direito Constitucional pela Damásio Educacional. Membro do Instituto Brasileiro de Ciências Criminais (IBCCRIM). Professor de Direito na Universidade do Vale do Itajaí (UNIVALI) e na Universidade do Contestado. Campus Mafra. Santa Catarina. Brasil. Delegado de Polícia. E-mail: alanpinheirodepaula@gmail.com.
} 


\begin{abstract}
The research addresses the issue of Animal Law with a focus on developing protection measures against abuse and mistreatment. The theme has evoked debates around the world, and has been gaining greater visibility, attention and interest with the repercussion of reports of abuse and mistreatment practices. Following the methodology of bibliographic research, the issue is approached in three aspects: first, a presentation at a historical and theoretical level, where the predominance of the anthropocentric conception and the contemporary criticisms that are aimed at it are emphasized. It is observed that the notion of "sentience" has been the pivot for a change in the paradigm that concerns the animal cause. Then, the protection laws in force in Brazil are considered, as well as the justifications for the last amendment proposal, at the end of 2019 , and the registration of the previous ones. Finally, the following questions arise: would the penalties imposed for ill-treatment at the national level be adequate and sufficient? Comparatively, in relation to the legislation of other countries, what is the status of the specific legal apparatus? It concludes by stating that, although the intensification of punitive measures play a special role in resolving cases of abuse, a significant change will only occur through updating the technicallegal aspect in line with the ethical-philosophical axis.
\end{abstract}

Keywords: Animal Rights. Mistreatment. Legislation.

\title{
1 INTRODUÇÃO
}

Algo de fato tem se alterado na compreensão da relação humano-animal ou ainda estaríamos numa etapa incipiente das demandas de liberação? A pergunta poderia ser respondida com um "sim" pelo público comum, que pode notar uma crescente empatia e atenção com relação à causa animal, e com um "não" dos ativistas que nutrem expectativas por mudanças mais radicais, como a total abolição do consumo de carne, dos experimentos com cobaias e dos produtos de origem animal, por exemplo. No meio termo entre essas duas demandas, a consideração com a senciência vem alterando o status do animal na legislação de vários países.

A presente pesquisa sobre proteção e direito animal se insere no grupo das abordagens mais amplas e integradoras, a que se pode designar como interdisciplinares. Tal abordagem tem se tornado usual na questão da causa animal sendo também adotada por vários pesquisadores que compõe as referências do presente estudo - visto ser difícil abordá-la sem a consideração a aspectos históricos, éticos e biológicos. A interdisciplinaridade tem como vantagem ser capaz de compor uma visão de conjunto que reúne diferentes áreas sobre o mesmo tópico. Dá-se assim 
uma associação entre aspectos diversos (éticos, formativos, jurídicos culturais, históricos, filosóficos) em torno à mesma questão.

A problemática se orienta pela injunção de três fatores que integram a questão do direito animal, com o fito de mostrar importância de fazê-los avançar juntos a fim de obter ganhos mais significativos a nível social. Começamos por discorrer sobre o compreensão histórico-filosófica sobre o animal, para, em seguida, pontuar a senciência (o reconhecimento da sua capacidade perceptiva, emocional e sensorial) como fator que demove e supera a reificação predominante. Cabe considerar como os animais são comumente rotulados e vistos da perspectiva antropocêntrica e as críticas a essa concepção.

Em seguida, considera-se as consequências jurídicas dessa compreensão social no direito brasileiro, nas questões sobre punição aos casos de maus tratos e abandono, além da tutela jurídica animal. Comparativamente, com relação à legislação de outros países, como é possível aprimorar o aparato jurídico específico no Brasil?

No estudo ora apresentado, verifica-se uma inadequação entre a lei específica em vigor e as concepções éticas em voga. Destaca-se que a legislação vigente não apresenta a suficiência devida em relação às demandas contemporâneas e quanto à previsão, expressa na Constituição Federal, sobre o dever público de não submissão dos animais à crueldade física e psíquica, visando ao próprio bem-estar do animal que merece ser tutelado como bem jurídico autônomo - algo que, na prática, não ocorre.

A metodologia utilizada na elaboração foi a de pesquisa bibliográfica: a partir da seleção de referências que expressam a posição e o pensamento dos autores sobre o tema em questão, se seguiu uma síntese expositiva com vistas às perguntas sobre a suficiência e adequação das leis nacionais de proteção animal. A pesquisa bibliográfica procede concatenando os aspectos históricos, filosóficos e jurídicos. Por fim, estabelece-se um comparativo com a alteração da legislação em outros países com relação à proteção e garantias do direito animal, e conclui-se que o status do Brasil é de atraso e relativa inadequação em consideração à senciência animal. 


\section{BREVE APRESENTAÇÃO DAS CONCEPÇÕES HISTÓRICO-FILOSÓFICAS SOBRE O ANIMAL}

Considerando o desenvolvimento da história da humanidade pelo historiador Yuval Noah Harari, na fase que antecede a chamada "revolução agrícola", relata-se que o homem sempre exerceu poder sobre os animais. Os cães foram os primeiros a terem aproximação e contato com o homem, há aproximadamente 15 mil anos. Eles o ajudavam a caçar, a lutar e a defender o território contra outros animais e inimigos. Com o passar do tempo, essa aproximação foi se intensificando até chegar ao primeiro relato de animal doméstico de que se tem notícia, encontrado enterrado junto ao esqueleto de uma mulher no norte de Israel (HARARI, 2017).

Grosso modo, desde tempos remotos, o animal é tido como ente subordinado à ação humana. Silva (2014) pontua os principais blocos históricos das concepções sobre o animal: após o viés cosmocêntrico, próprio dos filósofos pré-socráticos (Tales, Heráclito, Empédocles), haveria se sucedido uma investida antropocêntrica iniciada pelos sofistas da Grécia Antiga (de modo emblemático, pode-se considerar o homem "medida de todas as coisas" protagórico). A mesma concepção logocêntrica, que tem a capacidade racional-discursiva humana como centro, perpassa a filosofia platônica e aristotélica.

Os romanos deram continuidade à essa prevalência do domínio humano sobre o animal, que se refletiu diretamente nas categorias do direito romano, que enquadrava o animal como res (coisa). Dentro dessa visão do animal em relação ao ser humano predomina a concepção antropocêntrica durante toda a Idade Média, acirrada e remodelada no período do Renascimento. Atualmente, variadas correntes de pensamento vem alterando essa visão tradicional que remonta aos gregos da Antiguidade, bem como ao Novo Testamento:

O domínio incondicional dos homens sobre o reino animal passou ao longo da história por diversas etapas que solidificaram essa arcaica visão de mundo, vindo consolidada desde a filosofia helênica, passando pela gênese bíblica e chegando praticamente intocada até os dias de hoje. Ainda que a preocupação ecológica seja crescente, o debate acerca da condição dos animais não-humanos permaneceu, de certa forma, periférico até meados da década se setenta, quando uma série de estudos, antigos acadêmicos e livros reacendeu as discussões sobre o assunto, até então latentes (LOURENÇO, 2008, p. 201). 
O antropocentrismo é uma concepção de mundo que surgiu em correntes do pensamento filosófico na Antiga Grécia, pela qual se afirma o ser humano como parte central do cosmos. Basicamente, em razão de possuir poder de fala (o "animal racional" aristotélico), ele teria nascido para governar e imperar sobre outras espécies (Gênesis 1:26). Na antiguidade os animais eram tidos como um bem a serviço exclusivamente da espécie humana, sendo o homem o centro de referência para todas as coisas. Na época moderna, o homem se torna a régua e o compasso para mensuração e apreensão da realidade.

Entre os representantes do pensamento de cunho antropocêntrico ao longo da história ocidental a partir da Modernidade, destacam-se o filósofo francês René Descartes, ao considerar a superioridade humana a partir da análise da alma, e Immanuel Kant, ao considerar o ser humano como fim e não como meio (SOUZA, 2019). Arthur Schopenhauer, por sua vez, de quem os biógrafos relatam que era bastante simpático aos animais, fez duras críticas à filosofia kantiana devido ao tratamento que ela dispensou ao tema. O filósofo afirmava que a concepção kantiana estava respaldada na tradição judaico-cristã de uma maneira "travestida":

[...] Mostra-se, ao mesmo tempo, como esta moral filosófica [kantiana] que é, como foi acima exposta, uma teologia travestida depende totalmente da moral bíblica. A saber, porque a moral cristã não leva em consideração os animais. Estes estão de imediato também fora da lei na moral filosófica, são meras coisas, meros meios para fins arbitrários, por exemplo, para vivissecção, caçada com cães e cavalos, tourada, corrida de cavalos, chicoteamento até a morte diante de carroças de pedra inamovíveis etc. Que vergonha desta moral de párias, 'schandalas' e 'mletschas', que desconhece a essência eterna que existe em tudo o que tem vida e reluz com inesgotável significação em todos os olhos que vêem à luz do dia. Porém, aquela moral só reconhece e considera a única espécie que tem valor, a que tem como característica a razão, sendo esta a condição pela qual um ser pode ser objeto de consideração moral (SCHOPENHAUER, 1995, p. 72).

Em seu "Discurso sobre a Origem e Fundamentos da Desigualdade Entre Homens" (1754), Jean Jacques Rousseau já alterava a compreensão moderna e prenunciava a senciência como um fator distintivo determinante, para além da racionalidade:

Por esse meio, encerram-se também as velhas querelas sobre a participação dos animais na lei natural, porque é claro que, desprovdos de luzes e de liberdade, eles não podem reconhecer essa lei; mas, ligados até certo ponto à nossa natureza pela sensibilidade de que são dotados, considerar-se-á que 
eles também devem participar do direito natural e que o homem está sujeito em relação a eles, a certa espécie de deveres. De fato, parece, com efeito, que, se sou obrigado a não fazer nenhum mal a meu semelhante, é menos porque ele é um ser racional do que porque é um ser sensível, qualidade que, sendo comum ao animal e ao homem, deve ao menos dar a um o direito de não ser maltratado inutilmente pelo outro (ROUSSEAU, 2017, p. 37).

Ainda no campo filosófico, a concepção antropocêntrica frente ao animal dividiu opiniões também entre utilitaristas e contratualistas. Jeremy Bentham (1748-1832), por exemplo, defendeu o princípio do bem-estar e já abordava a senciência animal, pontuada na sua capacidade de sofrer.

Contemporaneamente, Peter Singer (1946-) e Tom Regan (1938-2017) trouxeram grandes contribuições à compreensão dos direitos dos animais e em prol da libertação dos mesmos em suas obras. Oferecendo uma contrapartida à visão antropocêntrica consolidada através das épocas, Regan se posicionou de forma divergente ao antropocentrismo cartesiano com a promoção da ideia de "dignidade animal". Essa noção defende o respeito pelos indivíduos, englobando animais não humanos (REGAN, 2005).

Não obstante, cumpre assinalar que o progresso das leis de proteção animal não acompanha ou não possui relação necessária com o desenvolvimento do respeito ao humano. Prova disso foi a "Tierschutzgesetz" alemã (literalmente, "Lei de proteção animal") aprovada por Adolf Hitler. Muitos líderes nazistas, como Hermann Göring e Heimrich Himmler, apoiavam entusiasticamente a pauta do Direito Animal, tendo esse último, inclusive, sido responsável pelo banimento da caça na Alemanha naquele período (KITCHEN, 2006). Hitler declarava que no novo Reich, nenhuma crueldade contra os animais seria permitida. Assim, tão logo ascendeu ao poder em 1933, foi regulamentado o transporte de animais em veículos automotores e estabelecido restrições em relação à vivissecção, desprezada, então, como "ciência judaica" (ARLUKE; SANDERS, 1996).

Conforme pontuado por Porto e Paccagnella (2017), as perspectivas e concepções éticas com relação ao animal podem ser apreciadas segundo as visões do antropocentrismo (nas variantes "tradicional" e "mitigado"), sencientismo e biocentrismo - este último, pautada no valor da vida e com a retirada do homem do centro de referência, a própria natureza passaria a titularizar direitos (BARATELLA, 2014 apud PORTO; PACCAGNELLA, 2017). 
No Brasil, prevalecem as concepções tradicionais de base moral cristã e a herança do aparato jurídico romano. Como acentuam Leite e Neto (2019, p. 249), "No direito romano os animais tornaram se propriedade humana, sendo tal herança adotada pelo ordenamento jurídico brasileiro refletido inclusive no Código Civil de 2002".

\title{
2.1 A SENCIÊNCIA ANIMAL
}

O termo "senciente" (adjetivo que se deriva do latim sentiente) descreve o ser que sente ou têm sensações. Essa definição conceitual, já bastante usual, é ainda pouco encontrada em dicionários comuns. De acordo com as recentes pesquisas científicas, os animais são considerados seres sencientes, ou seja, eles possuem capacidade emocional de sentir dor, medo, prazer, alegria e estresse, além de terem memórias e, até mesmo, saudades.

Apenas em julho de 2012, a comunidade científica reconheceu publicamente a existência da consciência dos animais, o que culminou na breve, porém contundente, "Declaração de Cambridge sobre a Consciência Animal”3, publicamente anunciada por David Edelman (Instituto de Neurociência em La Jolla, Califórnia), Philip Low (Universidade de Stanford) e Christof Koch (Instituto de Tecnologia da Califórnia). A declaração concluiu que:

\begin{abstract}
Animais não humanos possuem os substratos neuroanatômicos, neuroquímicos e neurofisiológicos dos estados de consciência, juntamente com a capacidade de exibir comportamentos intencionais. Consequentemente, o peso da evidência indica que os humanos não são os únicos a possuir substratos neurológicos que geram a consciência. Animais não humanos, incluindo todos os mamíferos e aves, e muitas outras criaturas, incluindo polvo, também possuem estes substratos neurológicos (DECLARAÇÃO, 2012).
\end{abstract}

De acordo com a pesquisa, os animais possuem consciência, ou seja, são sencientes. Isso pressupõe que o animal tem sensações como dor, fome, frio e emoções relacionadas àquilo que sente: medo, estresse e frustração. Se o animal possui substratos neurológicos, ele tem a percepção do que está ocorrendo consigo,

\footnotetext{
${ }^{3}$ A Declaração (trad. Moisés Sbardelotto) pode ser lida na íntegra em <http://www.ihu.unisinos.br/noticias/511936-declaracao-de-cambridge-sobre-a-consciencia-emanimais-humanos-e-nao-humanos>. Acesso em 20 mar. 2020.
} 
sendo capaz de aprender com experiências, de reconhecer seu ambiente, de distinguir e escolher sobre objetos, outros animais, além de interagir com o animal humano (SOUZA, 2019).

A declaração dos neurocientistas altera o quadro do entendimento jurídico, sendo a senciência um conceito que demarca a sensibilidade e a consciência animal. Neste sentido, Laerte Levai (2004), discorrendo sobre o princípio da senciência, esclarece a definição do termo e oferece argumentos para mostrar como o sofrimento gerado a qualquer ser (humano ou não humano) é abominável. Pontua, ainda, o efeito que esse novo reconhecimento deve surtir no âmbito jurídico.

Gary Francione, por seu turno, faz avançar a discussão pelo direito irrestrito do animal à vida. Não haveria modo de continuarmos negando aos animais não humanos um direito próprio, mesmo em detrimento da nossa possibilidade de avançar sobre eles.

[...] a morte é o maior dano para qualquer ser senciente, e que meramente ser senciente já implica, pela lógica, um interesse na existência continuada e alguma consciência desse interesse. Ser um ser senciente significa ter um bem-estar experiencial. [...] Os animais podem não ter pensamentos sobre a quantidade de anos que viverão, mas, em virtude de não terem interesse de não sofrer e em experienciar prazer, eles têm interesse de permanecerem vivos (FRANCIONE, 2013, p. 235).

O conceito de senciência vai além da capacidade de sentir dor e abrange o limite que distingue os seres vivos que podem e que não podem ter direitos. Francione defende que os seres sencientes possuem interesse em não sofrer. A despeito de não terem a capacidade de especular a quantidade de tempo de vida futura. Os animais possuem, em razão da senciência, interesse em permanecerem vivos.

Notoriamente, existe distinção entre a racionalidade humana e a percepção animal, mas esta última possui uma aproximação possível com a racionalidade humana. Para muitos, aceitar uma aproximação da racionalidade humana com racionalidade dos animais significaria diminuir o valor do homem e igualá-lo aos animais. No entanto, percebe-se que o referido estudo demonstra uma certa consciência nos animais: a consciência de si e do mundo. Em pleno século $\mathrm{XXI}$, os animais prosseguem sendo vítimas de maus tratos. Com frequência, são divulgados na mídia casos de animais submetidos a traumas e violência. A inefetividade no cumprimento das leis, bem como a mentalidade predominante da exploração e 
subordinação já enraizada na sociedade, torna os animais passíveis de serem acometidos a agressões físicas e psicológicas.

\section{AS LEIS BRASILEIRAS NA PROTEÇÃO ANIMAL}

Como afirma Delabary (2012, p. 838), entende-se por "maus tratos" o ato de submeter alguém a tratamento cruel, trabalhos forçados e/ou privação de alimentos ou cuidados. Esse crime é praticado pelos mais variados tipos humanos e os motivos envolvem aspectos culturais, sociais e psicológicos, sendo muitas vezes mesmo praticado sem a consciência de que tal ato é prejudicial: "Muitas pessoas praticam atos de maus tratos mesmo sem perceber. Quando um animal fica preso sem água e comida ou se fica debaixo do sol ininterruptamente, isso também é considerado crime devendo ser denunciado e punido".

Como assinala Souza (2019), os maus-tratos contra animais passam a ser criminalizados no Brasil na primeira metade do século XX, por meio do Decreto 24.645 de 1934, atualmente revogado. A promulgação deste expediente corroborou com o avanço do reconhecimento dos direitos e proibições de crueldade contra animais. $\mathrm{Na}$ sequência, foi instituída a Lei de contravenções penais (Decreto 3.688/41), tipificando como infração penal a crueldade contra animais, o que acarretava prisão simples de dez dias a um mês e multa.

Depois, veio a Lei n. 6.638 de 1979, que abordava a questão da vivissecção, revogada pela Lei n. 9.605/98 (Lei dos Crimes Ambientais ou Lei da Natureza). Essa última Lei, ainda em vigor, dispõe sobre sanções penais administrativas de crimes ambientais. Em especial destaca-se o Art. 32 que caracteriza como crime os maus tratos contra os animais.

Art. 32. Praticar ato de abuso, maus-tratos, ferir ou mutilar animais silvestres, domésticos ou domesticados, nativos ou exóticos:

Pena - detenção, de três meses a um ano, e multa.

$\S 1^{\circ}$ Incorre nas mesmas penas quem realiza experiência dolorosa ou cruel em animal vivo, ainda que para fins didáticos ou científicos, quando existirem recursos alternativos.

$\S 2^{\circ}$ A pena é aumentada de um sexto a um terço, se ocorre morte do animal (BRASIL, 1998). 
Assim, nossa principal lei de proteção aos animais é a Lei Federal 9.605/98, que ficou conhecida como Lei dos Crimes Ambientais. A Constituição Federal estabelece em seu artigo 225, Parágrafo $1^{\circ}$, que cabe ao Poder Público:

\begin{abstract}
VI - promover a educação ambiental em todos os níveis de ensino e conscientização pública para a preservação do meio ambiente;

VII - proteger a fauna e a flora, vedadas, na forma da lei, as práticas que coloquem em risco sua função ecológica, provoquem a extinção de espécies e submetam os animais a crueldade (BRASIL, 1988)
\end{abstract}

Mais recentemente, de acordo com o órgão oficial de notícias da Agência Senado 4 , o Plenário aprovou (vide sessão de 9 de setembro de 2020) o projeto que aumenta as penas para maus-tratos a cães e gatos (PL 1.095/2019). O texto, que havia sido aprovado na Câmara no final de 2019, agora segue para sanção. Segundo a proposta, a prática de abuso, maus-tratos, ferimento ou mutilação a cães e gatos será punida com uma pena maior de reclusão: dois a cinco anos, acompanhada de multa e proibição de guarda.

O projeto altera a Lei de Crimes Ambientais (Lei 9.605, de 1998), para aumentar as penas cominadas ao crime de maus-tratos aos animais, criando um item específico para cães e gatos, que são os animais domésticos mais comuns e principais vítimas dessa categoria de crimes. Como assinalado acima, a pena atual é de detenção de três meses a um ano, e multa, dentro de um item sem especificação, que inclui a todos os animais. A proposta tornaria mais rigorosa a punição por maustratos: enquanto a Lei de 1998 previa a detenção, geralmente cumprida em regime aberto ou semi-aberto, agora se prevê a pena de reclusão, em presídios de segurança máxima ou média:

\begin{abstract}
Ocorre que a detenção é aplicada para condenações mais leves e não admite que o inicio do cumprimento seja no regime fechado. Como regra geral, a detenção é cumprida em regime aberto ou semiaberto, conforme estabelece o art. 33 do nosso Código Penal. Dessa forma, ao determinar pena de reclusão, de um a quatro anos, para a prática de crimes de maus tratos, este Projeto visa aumentar o rigor legal com o objetivo punir e coibir a prática desses delitos. A pena de reclusão é aplicada a condenações mais severas, o regime de cumprimento pode ser fechado, semiaberto ou aberto, e normalmente é cumprida em estabelecimentos de segurança máxima ou media, de acordo com o art. 33 do Código Penal (BRASIL, 2019).
\end{abstract}

\footnotetext{
4“Aumento da pena para quem maltratar cães e gatos vai à sanção". Fonte: Agência Senado.

Disponível em: https://www12.senado.leg.br/noticias/materias/2020/09/09/aumento-da-pena-paraquem-maltratar-caes-e-gatos-vai-a-sancao. Acesso em: 19 set. 2020.
} 
É digno de nota que o mesmo projeto, de autoria do deputado federal Fred Costa (Patriota-MG), assinale o impacto e a influência da comoção virtual que suscitou um caso ocorrido em 2019 como parte da justificativa da proposta de alteração da Lei de 1998:

\begin{abstract}
Recentemente, a forma brutal como um cachorro foi morto dentro de um supermercado Carrefour, em Osasco, São Paulo, chocou o País. O animal foi espancado e envenenado por um segurança do local, no dia 28 de novembro passado, e acabou não resistindo aos ferimentos. Internautas, ativistas pelos direitos dos animais, celebridades e políticos se manifestaram publicamente contra o bárbaro crime. Uma mobilização fez com que cerca de um milhão e meio de pessoas assinassem uma petição exigindo a punição do funcionário (BRASIL, 2019).
\end{abstract}

A menção comprova de que modo, na história recente, a questão da causa animal vem ganhando relevância crescente no meio social virtual. Observa-se, portanto, que essa atenção pública é capaz de surtir efeito e servir de apoio às propostas de alteração na legislação. Junto a isso, a visão do senso comum sobre o animal vem se alterando, gradativamente, a partir da sua base teórica, pelo apelo de entidades defensoras da causa e medidas educacionais a nível institucional.

Embora possa se observar uma crescente comoção e indignação social com respeito aos casos de abuso que se tornam públicos, a celeridade das penalidades impostas não tem feito jus ao clamor popular. Nota-se que o Brasil é um país marcado pela impunidade. É patente o fato de que a taxa de resolução de homicídios não passa de $8 \%$ a nível nacional (segundo dados levantados pelo Conselho Nacional do Ministério Público, em relatório detalhado de 2014, do Ministério da Justiça) e com relação aos animais, não é diferente.

Em contrapartida aos casos de abuso e violência, há variadas organizações trabalhando ativamente em prol da causa animal. Tais organizações dependem do auxílio da população na apuração dos casos de denúncia, ressaltando-se a importância da comunicação de abuso de animais às autoridades públicas, como no registro de boletim de ocorrência. Desse modo, essas organizações encontram respaldo para que consigam solucionar o problema e oferecer proteção ao animal. 
Desde março de 2002, o cidadão catarinense tem a possibilidade de efetuar o registro de boletim de ocorrência por via eletrônica na delegacia virtual ${ }^{5}$ - ferramenta disposta pela Polícia Civil de Santa Catarina. O objetivo é oferecer agilidade, praticidade e confiabilidade no registro de ocorrências por via eletrônica (FRANZONI, 2019). Ao presenciar situações de abandono ou maus tratos contra animais, ou que tome conhecimento dessas práticas, o cidadão poderá fazer uso do registro em ambiente virtual com discrição, sem a necessidade de deslocamento a uma unidade policial.

Entre as formas institucionalizadas de maus tratos contra os animais domésticos, podemos citar o emprego dos mesmos em experimentos científicos. Esse uso já bastante debatido, no entanto, não chegou a ser abolido do ordenamento jurídico por completo. $\mathrm{O}$ abandono animal e o uso para fins lucrativos também se incluem como forma de maus tratos. Grande quantidade de animais também padece por envenenamento e outros são descartados no lixo. Embora enquadrado como crime ambiental, a crueldade contra os animais não humanos é uma realidade recorrente no Brasil. Ainda que previsto na Constituição Federal, a conscientização ou reconhecimento popular para a urgência dessa situação, por parte de órgãos oficiais, é precária. Entretanto, a atuação dos ativistas em ambiente virtuais é crescente.

Com relação ao uso de animais em experimentos científicos, já em 1860, um fato emblemático foi decisivo para a discussão sobre o estabelecimento de limites ao uso de animais como cobaias em experimentos de laboratório. O eminente fisiologista francês Claude Bernard afirmava que o uso de animais vivos era indispensável para experimentações, por isso, mantinha um laboratório e um biotério nos porões de sua própria casa. Cansadas de ouvir os gritos de animais que diariamente eram torturados, a esposa e a filha de Claude o abandonaram e fundaram a primeira sociedade francesa em defesa dos animais (GOLDIM; RAYMUNDO, 1997).

A fundação dessa primeira associação inspirou o surgimento de diversas outras sociedades protetoras, assim como motivou a criação de leis específicas. Um dos requisitos para uso de animais em projetos científicos é colocá-los como última alternativa na necessidade de testes. Em razão da senciência, eles deveriam ser

\footnotetext{
${ }^{5}$ A Delegacia de Polícia Virtual é um serviço de registro de ocorrências via Internet, disponível no sítio eletrônico: <https://www.pc.sc.gov.br/servicos/delegacia-virtual> Acesso em: 30 de jun. 2020.
} 
preteridos ao emprego experimental e, em último caso, receber a atenção e cuidado devidos antes e após a realização do experimento.

Como afirmado acima, a visão antropológica em relação ao animal impulsiona sua exploração de maneira generalizada. Quando o animal deixa de servir, este é descartado como objeto sem uso. Outro crime bastante comum baseado, direta ou indiretamente, nesse viés é o abandono de animais. Além do sofrimento animal, o abandono gera prejuízos ecológicos, sanitários, públicos e de bem-estar animal. A estimativa da WSPA (Sociedade Mundial de Proteção Animal) é que $75 \%$ dos cães do mundo estejam nas ruas (SOUZA; FERREIRA, 2018).

A “Declaração Universal dos Direitos dos Animais", proposta cuja redação final data de 1978, de autoria do belga Georges Heuse, visava criar parâmetros jurídicos para os países membros da ONU (Organização das Nações Unidas) e é comumente citada com esse fim. No entanto, cumpre ressalvar que, diferente das informações replicadas por muitos artigos, a Declaração não foi redigida ou chancelada como documento oficial da ONU ou da UNESCO (PORTO; PACCAGNELLA, 2017).

O ativismo virtual, lenta e gradativamente, começa a surtir efeito na mentalidade coletiva, mas ações ordenadas são requeridas:

\footnotetext{
Nos tempos atuais, a população está mais consciente no que respeita a proteção dos animais, mas precisa melhorar e os animais que estão sendo maltratados devem ser defendidos. Ser protetor ou defensor não se resume em atitude isolada, e sim em atos constantes, como por exemplo: não basta avisar a um protetor que o animal está sendo maltratado ou ficar na internet simplesmente solicitando ajuda. Fatos como esses, de modo isolado, não tornam o homem um protetor ou defensor, e sim, simpatizantes da causa (MURARO; ALVES, 2014, n. p.)
}

Ao longo dos anos, os ativistas têm atuado para que a sociedade renove seus conceitos e ideias. Pode-se afirmar, de modo geral, que boa parte da população passou a considerar o animal com outros olhos, dedicando-lhes mais compaixão, cuidado e respeito. Em suma, vem ganhando maior expressão uma visão mais comedida e menos brutal com relação ao animal. 


\section{O ORDENAMENTO JURÍDICO BRASILEIRO E INTERNACIONAL}

A despeito dos avanços ocorridos ao longo do tempo em prol dos direitos dos animais em vários países, o Ordenamento Jurídico Brasileiro assegurou apenas um mínimo de direitos e proteção a esses seres, sendo determinante, ainda, o pensamento romano arcaico de que os animais são meras coisas. No Brasil, os animais não alcançaram o patamar de sujeitos de direitos.

Conforme assinala Célia Souza, nesse mesmo raciocínio, aquele que espanca e mata um animal doméstico terá uma pena ínfima (Artigo 32 da Lei 9.605/98), beneficiada por força de estar inserida na classificação de crimes de menor potencial ofensivo. Nesse sentido, percebe-se que o bem jurídico maior, que é a vida do animal, está despida da proteção adequada exigida pela contribuição. Compreende-se que os fundamentos que sustentam a proibição da crueldade na nossa legislação estão ligados a uma proteção indireta ao ser humano: o especismo antropocêntrico é o que impera no nosso ordenamento jurídico (SOUZA, 2019).

$\mathrm{Na}$ Constituição, a proteção animal se insere no direito humano e à conservação do meio ambiente. Nesse sentido, o Brasil está atrasado, comparativamente com boa parte dos países. O estudo de Souza e Souza (2018) agrega informações sobre as propostas de alteração de lei brasileiras e mostra o período em que outros países retiraram seus animais da categoria de "coisa", reconhecendo-lhes a sensibilidade, e os elevaram à categoria de bens (ou ainda a um patamar intermediário, como no caso de Portugal). Assim, deu-se a alteração no código civil austríaco em 1988; na Alemanha, primeiro país da União Europeia que passou a garantir direitos fundamentais aos animais, em 2002. A Suíça, por sua vez, fez modificações em 2003. A França fez alterações no seu quadro mais recentemente, em 2015, a Holanda em 2011 e o México em 2017. Em Resumo:

No campo legislativo, o estatuto jurídico dos animais vem sendo modificado em países que adotam o sistema romano-germânico. É o caso, como visto, dos Códigos Civis austríaco (modificado em 1988); alemão (em 1990); suíço (em 2003); holandês (em 2011); francês (em 2015); e português (em 2016). Em 2017, foi a vez da Constituição do México, ao reconhecer os animais como seres sencientes e destinatários de tratamento digno e respeito à vida e à integridade física, sendo sujeitos de consideração moral. O próximo país a caminhar para a reformulação do estatuto jurídico dos animais é a Espanha (SOUZA; SOUZA, 2018). 
Souza e Souza (2018) listam, ainda, as propostas legislativas que tendem à modificação do status jurídico dos animais, os quais gerariam efeitos diretos sobre o Código Civil. Na ordem cronológica das proposições estão: o projeto de lei 215/2007, (do deputado Ricardo Tripoli), que visa à criação de um Código Federal de Bem-Estar Animal. O projeto de Lei 3.676/2012 (deputado Eliseu Padilha) propõe a criação de um Estatuto dos Animais, levando em conta o status de senciência. Destaca-se ainda o Projeto de Lei 6.799/2013 (deputado federal Ricardo Izar), que também objetiva conferir aos animais não humanos o tratamento de seres sencientes, como ocorreu na Cidade do México.

Posteriormente, foi formulado o projeto de Lei 7.991/2014, (deputado Eliseu Padilha), que propõe um acréscimo ao artigo $2^{\circ}$ do Código Civil, e o projeto de Lei 650/2015 (da senadora Gleisi Hoffmann), que propôs a criação de um Código de Proteção e Defesa do Bem-Estar dos Animais.

Já no Projeto de Lei 351/2015, os animais passariam a constar no Código Civil como bens, deixando o status de res (herança do legado romano), deixariam assim de ter apenas valor econômico, como coisa. Os bens podem possuir valor imaterial, entre os quais como a vida e a liberdade. Isso significaria uma grande mudança do paradigma jurídico na causa animal. O propositor, senador Antonio Augusto Anastasia, autor da matéria, afirmou que, ao deixarem de ser considerados "coisas", sob o ponto de vista legal, reconhecer-se-ia, de alguma forma, que eles não podem ser descartáveis ou abandonados 6 . O que representa um passo jurídico importante.

\section{CONSIDERAÇÕES FINAIS}

Vários teóricos têm apostado na tentativa de desconstruir paradigmas e concepções tradicionais a fim de que isso surta efeito na redução das crueldades cometidas, bem como na própria relação humano-animal, de maneira mais geral. Ao dotar o animal não humano de direitos caberia tornar essa responsabilidade inultrapassável e encontrar meios de garantir sua eficácia protetiva.

\footnotetext{
${ }^{6}$ Cf. Projeto de Lei muda status de animais no Código Civil. Correio Braziliense (02/08/2015). Disponível em: < correiobraziliense.com.br/app/noticia/brasil/2015/08/02/internabrasil,492982/projeto-de-lei-muda-status-de-animais-no-codigo-civil.shtml> Acesso em: 15 set. 2020.
} 
Como mencionamos acima, os pensamentos filosóficos de Descartes e Kant dão lastro à concepção antropocêntrica da Modernidade que se perpetua até a atualidade. Por sua vez, Schopenhauer, no que concerne aos animais e à moral, criticou duramente o pensamento kantiano apontando sua base judaico-cristã. Desde então, outros autores no campo filosófico e antropológico tem tecido vieses interpretativos com ênfase na desconstrução da tradição Moderna, sobretudo a mecanicista, de base cartesiana.

Toda alteração jurídica é precedida por uma reflexão e teorização a níveis mais profundos, que coloca em xeque as concepções arraigadas num dado período ou época. Entende-se que a contestação sobre o status do animal diante do humano requer uma consideração acerca das crenças e pressupostos vigentes. A profundidade em que tais pressupostos modernos se radicam explica, parcialmente, a dificuldade de alterar um quadro jurídico determinado.

Outro fator relevante, ainda, passa pela disseminação de informações ao cidadão comum, pela qual poderia assimilar os novos paradigmas e rever seu comportamento presente. Observa-se que uma modificação da compreensão geral (moral e espiritual) ou concepção do senso comum de época acerca de uma dada realidade, é responsável por demandar alterações de ordem técnico-jurídica ou solidificar alterações já propostas. Nesse sentido, caminham juntos: cultura, costumes, economia, educação, senso de sacralidade, entre outros fatores decisivo para a composição do imaginário popular.

A construção de uma Dignidade Animal, alicerçada em pesquisas científicas de impacto, estudos filosóficos relevantes e na conscientização popular, é imprescindível para efetivação das novas propostas de alterações no campo jurídico. Na direção de uma atualização desse status, vimos que a citada "Declaração de Cambridge" oferece respaldo ao demarcar a senciência animal como critério, bem como o relevante trabalho de filósofos como Peter Singer (2013), originalmente publicado em 1975, que deixou contribuição significativa para a definição de "especismo". A isso se soma a reverberação de denúncias de casos notórios de violência contra animais nas redes sociais, por parte de cidadãos comuns, ONGs, ativistas e entidades de defesa. Tais fatores vêm surtindo certo efeito sobre a mentalidade do grande público.

A consideração sobre a senciência tem embasado modificações no ordenamento jurídico de vários países. Postula-se que nenhum ser senciente deve 
ser submetido ao sofrimento e à dor, na medida em que não há justificativa de ordem moral de interesse legítimo para tanto. Paulatinamente, opera-se uma redefinição dos parâmetros de compreensão mais vulgares sobre a natureza e a finalidade do animal, na medida em que o antropocentrismo então predominante na história ocidental é balançado pelo questionamento das bases da tradição greco-romana.

Segundo Souza (2019), no aspecto jurídico, a Constituição Federal pede proteção por meio do mandado expresso de criminalização, previsto no artigo 225 parágrafo $1^{\circ}$ inciso VII. Não se trata de conferir aos animais a igualdade de direitos concedida aos humanos, mas de reconhecer sua peculiaridade, como personalidade autônoma sui generis, visto serem eles dotados de percepção, sensação, e por isso, terem direito à vida digna, respeito e compaixão. No entanto, até a presente data o referido mandado expresso de criminalização não possui o condão de proteger este bem jurídico de maneira eficaz e adequada. Isso ocorreria, mais uma vez, justamente pela predominância da visão antropocêntrica e especista na nossa legislação.

A condição biológica assemelhada, firmada por meio da compreensão de que homem e animal se incluem na categoria de seres vivos sencientes, capazes de ligação mútua por afeição, gestos, empatia e interações especiais, os tornaria dignos de proteção e também adequada punição àqueles que lhe imprimam sofrimento. A dignidade dos animais é buscada para além de argumentos morais e se pauta em argumentos técnicos, científicos e jurídicos penais, que nos remetem a uma reflexão constante acerca da forma como o animal é tratado. De uma perspectiva econômica, encontra-se a influência que o lucro de grandes empresas (indústria farmacêutica e cosmética, por exemplo) acumulado a partir do uso de animais em testes ou como matéria-prima.

Conclui-se destacando o fato de que as leis brasileiras ainda deixam grande margem à impunidade dos agentes que praticam condutas de crueldade. Como foi visto, nossa legislação penal é inadequada e desatualizada, se se leva em conta as recentes pesquisas sobre a essência do animal, portanto, necessita de reparos e alterações estruturais.

Os apontamentos da Constituição, da Lei de 1998 e da proposta de alteração (2019) aqui mencionados assinalam caminhos para aumento da punição e maior conscientização-comoção pública, mas não há, ainda, uma alteração do status ou categoria do animal no Código Civil. O inciso VI, do parágrafo 1 de incumbências do 
Poder Público, faz menção à promoção da educação ambiental e conscientização pública para a preservação do meio ambiente. Desse modo, entre outras coisas, cabe aumentar as campanhas informativas junto ao cidadão para a conscientização da participação ativa na preservação da flora, das nascentes, dos cursos d'água e no combate aos maus-tratos dos animais.

\section{REFERÊNCIAS}

ARLUKE, Arnold; SANDERS, Clinton. Regarding animals. Pennsylvania: Temple University Press, 1996.

BRASIL. Aumento da pena para quem maltratar cães e gatos vai à sanção. Agência Senado. Brasília: 09 set. 2020. Disponível em: <https://www12.senado.leg.br/ noticias/materias/2020/09/09/aumento-da-pena-para-quem-maltratar-caes-e-gatosvai-a-sancao> Acesso em: 19 set. 2020.

. Constituição da República Federativa do Brasil, promulgada em 05 de outubro de 1988 Disponível em: <http://www.planalto.gov.br/ccivil_03/constituicao/ constituicao.htm>. Acesso em: 21 mar. 2020.

. Diário Oficial da União. Brasília: 13 fev. 1998. Disponível em:

<http://bit.ly/1La6hQT>. Acesso em: 24 mar. 2020.

. Lei Federal 9.605/98. Brasília: 1998. Disponível em:

<http://www.planalto.gov.br/ccivil_03/leis/L9605.htm.> Acesso em: 19 set. 2020.

. Projeto de Lei 1095/2019. Brasília: fev. 2019. Disponível em:

<https://www.camara.leg.br/proposicoesWeb/prop_mostrarintegra?codteor $=1714454$ >. Acesso em: 19 set. 2020.

DECLARAÇÃO DE CAMBRIDGE SOBRE A CONSCIÊNCIA ANIMAL. Disponível em: <http://www.ihu.unisinos.br/noticias/511936-declaracao-de-cambridge-sobre-aconsciencia-em-animais-humanos-e-nao-humanos>. Acesso em: 30 ago. 2020.

DELABARY, Barési Freitas. Aspectos que influenciam os maus tratos contra animais no meio urbano. Revista Eletrônica em Gestão, Educação e Tecnologia

Ambiental, Santa Maria, v.5, n. 5, 2012.

FRANCIONE. Gary L. Introdução aos direitos dos animais. Campinas: Unicamp, 2013.

FRANZONI, Leonardo. Delegacia Virtual de SC começa a registrar boletins de ocorrência de maus-tratos contra animais. Florianópolis. 05 nov. 2019. Disponível em: <https://www.sc.gov.br/noticias/radio/delegacia-virtual-de-sc-comeca-a-registrarboletins-de-ocorrencia-de-maus-tratos-contra-animais>. Acesso em: 30 jul. 2020. 
GOLDIM, Jose Roberto; RAYMUNDO, Marcia Mocellin. Pesquisa em saúde e os direitos dos animais. 2.ed. Porto Alegre: HCPA, 1997.

HARARI, Yuval Noah. Sapien: uma breve história da humanidade, 29. ed. Porto Alegre: Janaina Marco Antônio, 2017. Disponível em: <https://rl.art.br/arquivos/ 6106221.pdf?1504713449>. Acesso em: 5 fev. 2020.

KITCHEN, Martin. A history of modern Germany, 1800-2000. New Jersey: Blackwell Publishing, 2006.

LEITE, Thiago Alexandre de Oliveira; NETO, Jorge José Maria. A evolução dos direitos inerentes ao bem-estar dos animais. In: MACHADO, Felipe Santana; MOURA, Aloysio Souza. (Org). Educação, meio ambiente e território 2. Ponta Grossa: Atena Editora, 2019.

LEVAI, Laerte Fernando. Direito dos animais. Campos do Jordão: Editora: Mantiqueira, 2004.

LOURENÇO, Daniel Braga. Direito dos animais: fundamentação e novas Perspectivas.1. ed. Porto Alegre: Sergio Antônio Fabris Editor, 2008.

MURARO, Celia Cristina; ALVES, Darlei Novais. Maus tratos contra animais. Revista Âmbito Jurídico, Rio Grande, v. 17, n. 122, 2014. Disponível em: $<$ https://ambitojuridico.com.br/cadernos/direito-ambiental/maus-tratos-contraanimais/> Acesso em: 20 jun. 2020.

PORTO, Adriane Célia Souza; PACCAGNELLA, Amanda Formisano. A verdadeira natureza jurídica da Declaração Universal dos Direitos dos Animais e sua força como carta de princípios. Revista Âmbito Jurídico, São Paulo, a. 20, n. 165, 2017.

REGAN, Tom. Jaulas vazias: encarando o desafio dos direitos animais. Porto Alegre: Lugano, 2006.

REGIS. Arthur Henrique de Pontes; CORNELLI, Gabriele. Situação jurídica dos animais e propostas de alterações no Congresso Nacional. Revista Bioética. Brasília. v. 25, n. 1, jan./apr. 2017. Disponível em: <https://www.scielo.br/pdf/bioet/ v25n1/1983-8042-bioet-25-01-0191.pdf>. Acesso em: 6 fev. 2020.

ROUSSEAU, Jean-Jacques. A origem da desigualdade entre os homens. São Paulo: Penguin, 2017.

SILVA, Chiara Michelle Ramos Moura da. Direito animal: uma breve digressão histórica. Conteúdo Jurídico. Brasília-DF. Disponível em:

<https://conteudojuridico.com.br/consulta/Artigos/39899/direito-animal-uma-brevedigressao-historica> Acesso em: 23 set. 2020.

SINGER, Peter. Libertação animal. São Paulo: WMF Martins Fontes, 2013. 
SOUZA, Célia Renina Nirlander. 0 crime de crueldade contra animais não humanos à luz do bem jurídico-penal. Rio de Janeiro: Lumen Juris, 2019.

SOUZA, Fernando Speck; SOUZA, Rafael Speck. A tutela jurídica dos animais no Direito Civil Contemporâneo (Parte 3). Conjur: 2018. Disponível em:

https://www.conjur.com.br/2018-jun-04/tutela-juridica-animais-direito-civilcontemporaneo-parte> Acesso em: 20 set. 2020.

SOUZA, Alinne Silva de; FERREIRA, Adriano Fernandes. Direitos dos animais domésticos: análise comparativa dos estatutos de proteção. Revista Paradigma, Ribeirão Preto, a. 20, v. 24, n. 2, p. 98-118. 2015. Disponível em:<http://www9.unaerp.br/revistas/index.php/paradigma/article/view/97-117/pdf>. Acesso em: 30 mar. 2020.

SCHOPENHAUER, Arthur. Sobre o fundamento da moral. São Paulo: Martins Fontes, 1995.

Artigo recebido em: 21/08/2020

Artigo aceito em: 07/10/2020

Artigo publicado em: 27/10/2020 